\title{
The Role of Indian Ocean Sea Surface Temperature in Forcing East African Rainfall Anomalies during December-January 1997/98
}

\author{
M. LATIF AND D. Dommenget \\ Max-Planck-Institut für Meteorologie, Hamburg, Germany \\ M. DIMA \\ Faculty of Physics, University of Bucharest, Bucharest-Magurele, Romania
}

A. GRÖTZNER

Max-Planck-Institut für Meteorologie, Hamburg, Germany

8 September 1998 and 5 May 1999

ABSTRACT

\begin{abstract}
The role of anomalous Indian Ocean sea surface temperature (SST) in forcing east African rainfall anomalies during December-January 1997/98 has been investigated by means of atmospheric model response experiments. It is shown that the strong precipitation anomalies that led to severe flooding over eastern equatorial Africa can be directly related to the contemporaneous changes in the Indian Ocean's SST. The authors' set of ensemble experiments prescribing SST anomalies in different ocean basins indicates further that the El Niño-related SST anomalies in the equatorial Pacific did not directly drive the changes in the climate over eastern Africa.
\end{abstract}

\section{Introduction}

The dominant mode of tropical interannual climate variability is the El Niño-Southern Oscillation (ENSO) phenomenon (Philander 1990). Since ENSO originates in the tropical Pacific [see, e.g., the ENSO theory Tropical Ocean Global Atmosphere review paper by Neelin et al. (1998)], most studies on tropical interannual variability have concentrated so far on this region. The role of the other two tropical oceans, the tropical Atlantic and Indian Oceans, in forcing climate anomalies is less well understood. Here we present some evidence for an active role of the tropical Indian Ocean in forcing climate anomalies over eastern equatorial Africa. However, we restrict ourselves in this short note to a case study investigating the origin of the eastern equatorial African rainfall anomalies during December-January 1997/98 only. This period was characterized by numerous climate anomalies all over the world, and many of these anomalies were predicted with coupled models (e.g., Stock-

Corresponding author address: M. Latif, Max-Planck-Institut für Meteorologie, Bundesstrasse 55, D-20146 Hamburg, Germany

E-mail: latif@dkrz.de dale et al. 1998). Most of these anomalies were forced directly by the Pacific SST anomalies associated with the record El Niño 1997/98. However, there are indications that eastern equatorial African rainfall anomalies were not, and we shall show below that the Indian Ocean SST anomalies rather than the Pacific SST anomalies forced the anomalous rainfall over eastern equatorial Africa during the period considered. We would like to point out that we address in this note the origin of the eastern equatorial African rainfall anomalies during December-January 1997/98 only. In order to do this, we conducted ensembles of atmosphere model experiments with prescribed SSTs in different ocean basins. We neither attempt to provide a complete picture of the role of Indian Ocean SSTs in global climate, nor do we investigate the participitation of the Indian Ocean in the ENSO phenomenon.

Many studies have addressed the predictability of rainfall anomalies in different regions of the African continent both on interannual and interdecadal timescales and their relationships to SST anomalies and atmospheric circulation changes. Folland et al. (1986), for instance, show a remarkable relationship between Sahelian rainfall anomalies and global-scale SST anomalies on interdecadal timescales, while tropical Atlantic and Pacific SST anomalies appear to be more 


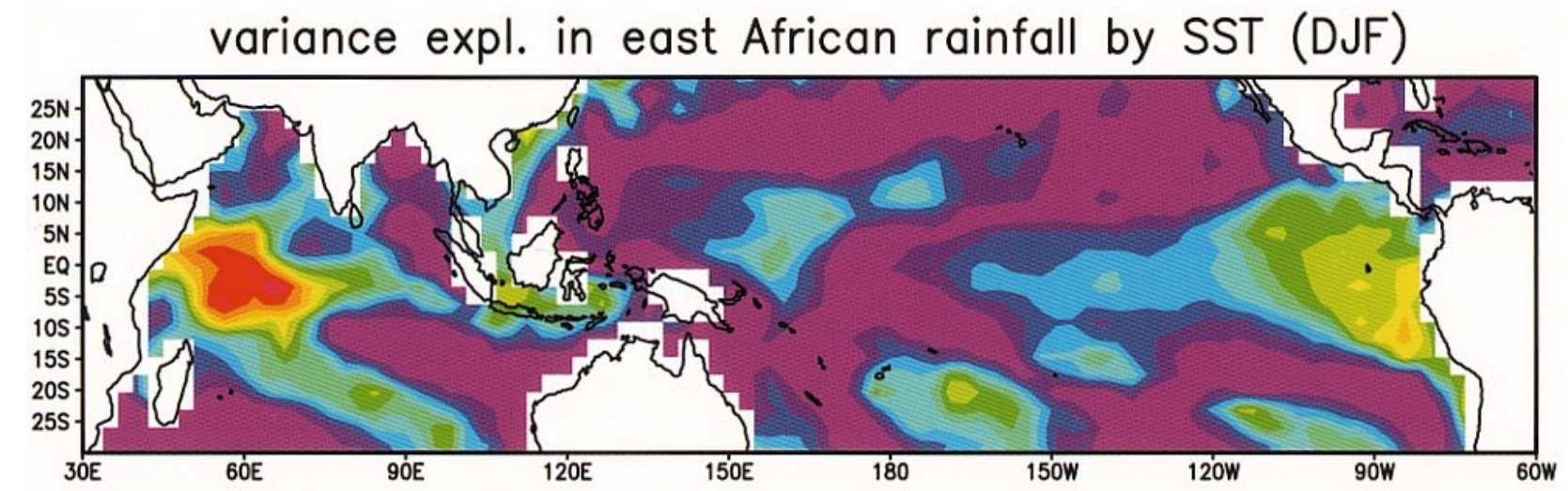

\begin{tabular}{lllllllllll|l|l|l|l}
\hline & & & & & & & & & & & & & & \\
\hline
\end{tabular}

FIG. 1. Variances explained in an index of eastern equatorial African rainfall anomalies by the SST anomalies in the Indian and Pacific Oceans for the winter season (DJF) and the period 1979-98. The eastern equatorial African rainfall index is an area average over the region $5^{\circ} \mathrm{N}-5^{\circ} \mathrm{S}$ and $35^{\circ}-50^{\circ} \mathrm{E}$. The rainfall and SST data were obtained from the datasets of Reynolds and Smith (1994) and Xie and Arkin (1997), respectively.

relevant at interannual timescales (Palmer 1986; Folland et al. 1991; Rowell et al. 1992). Some evidence for a relationship between rainfall in Guinea and eastern equatorial Atlantic SST anomalies on interannual timescales has been reported by Ward (1998). An apparent relationship between Moroccan rainfall variability and the North Atlantic oscillation has been described by Lamb and Peppler (1987, 1988). Lamb and Peppler (1991) give a nice summary on West African rainfall variability. The rainfall in southern Africa is affected by ENSO (Ropelewski and Halpert 1989). Cane et al. (1994), for instance, show that Zimbabwean rainfall and maize yield depend strongly on eastern equatorial Pacific SST anomalies.

The role of Indian Ocean SSTs in climate variability has been also discussed in a number of papers. Nicholls (1989), for instance, describes a relationship between Indian Ocean SST anomalies and Australian winter rainfall. Makarau and Jury (1997) find a relationship between summer rainfall in Zimbabwe and Indian Ocean SSTs. Arpe et al. (1998) demonstrate in a modeling study that moderate changes in the northern Indian Ocean SSTs may affect the Indian summer monsoon rainfall. Here we investigate by means of atmosphere model experiments the role of Indian Ocean SST anomalies in driving eastern equatorial African rainfall anomalies during December-January 1997/98. This period was characterized by very strong rainfall anomalies that led to severe flooding in this region. We have picked this particular time period because both the Indian Ocean SST anomalies and the rainfall anomalies over eastern equatorial Africa have been highly anomalous. We felt that if the strong Indian Ocean SST anomalies observed during winter 1997/ 98 would not exert a strong impact on eastern African climate, then it would be unlikely that they would on other occasions, when Indian Ocean SST anomalies are less well developed. As such our modeling study should be considered as a pilot study, a first step in investigating the role of the Indian Ocean SSTs in forcing East African climate anomalies.

Anomalously strong rainfall over eastern equatorial Africa is often observed during warm ENSO extremes (El Niños; Ropelewski and Halpert 1989). However, an analysis of observed rainfall and SST anomalies (not shown) revealed that only about $20 \%$ of the rainfall variability in winter (DJF) over eastern equatorial Africa can be attributed directly to the SST anomalies in the eastern equatorial Pacific, as measured by the Niño3 index. The larger part of the variability in eastern equatorial African rainfall is related to Indian Ocean SST anomalies. This is demonstrated by Fig. 1, which shows the variance explained in eastern equatorial African rainfall anomalies (averaged over the region $5^{\circ} \mathrm{N}-5^{\circ} \mathrm{S}$ and $35^{\circ}-50^{\circ} \mathrm{E}$ ) by the $\mathrm{SST}$ anomalies in the Indian and Pacific Oceans in the winter season during the period 1979-98. Relatively high values are found in the western tropical Indian Ocean, with the highest explained variances in the southwestern part of the basin. In contrast, the SST anomalies in the Pacific do not contribute strongly to the rainfall variability. A very strong SST anomaly was observed in 
the southwestern equatorial Indian Ocean during winter 1997/98 (Fig. 2), and the impact of this SST anomaly on the rainfall over eastern Africa is the topic of this paper.

Our note is organized as follows. We describe in section 2 the experimental setup and in section 3 the results of our response experiments with SST anomalies in different ocean basins. The note is concluded with a discussion in section 4 .

\section{Experimental design}

In order to demonstrate the connection between Indian Ocean SST and eastern equatorial African rainfall, we conducted a series of atmospheric response experiments with the atmospheric general circulation model ECHAM3 described in detail by Roeckner et al. (1992). The model has been used at T42 $\left(2.8^{\circ} \times 2.8^{\circ}\right)$ and T2 1 $\left(5.6^{\circ} \times 5.6^{\circ}\right)$ resolutions. SST anomalies were prescribed in different ocean basins (Fig. 2): the tropical Indian Ocean (Fig. 2a), the tropical Pacific Ocean (Fig. 2b), and both the tropical Indian and Pacific Oceans. The "Indian Ocean-only" experiment has been performed with both the T42 and T21 models, while the other two experiments have been performed at T21 resolution only. The SST anomalies obtained from the dataset of Reynolds and Smith (1994) have been averaged over the months December 1997 and January 1998 and held constant during the integrations, and ensembles of five 90-day integrations with different initial conditions were conducted. The results were averaged over all 90 days and the ensemble mean responses are shown. Control runs of 30- and 50-yr lengths forced by climatological SSTs serve as the reference runs for the T42 and T21 models, respectively. A $t$ test has been applied to assess the statistical significance of the results, and the response is shown only in those regions in which the values exceed the $95 \%$ confidence level.

We have chosen the two months December-January $1997 / 98$ since rainfall anomalies in our target region, eastern equatorial Africa, were strongest during this period. It should be noted that strong rainfall anomalies were observed over eastern equatorial Africa also in fall, which resulted probably from a characteristic eastwest dipole in Indian Ocean SST. Our study, however, does not address the origin of the anomalies observed in fall.

\section{Response experiments}

Our first experiment was performed by forcing the model at T42 resolution by the Indian Ocean SST anomalies (Fig. 2a) only. This SST anomaly pattern is characterized by a large-scale warming of the tropical Indian Ocean, with strongest anomalies in the Southern Hemisphere, extending from the east coast of equa- torial Africa in a southeastward direction to the west coast of Australia. The model's rainfall response to the Indian Ocean SST anomaly is remarkably similar to the rainfall anomalies observed during December 1997 and January 1998 both in pattern and amplitude (Fig. $3)$. This indicates that the Indian Ocean SST anomalies were instrumental in causing the severe flooding over eastern equatorial Africa during winter 1997/98. Both the observations and the model response show rainfall anomalies over eastern equatorial Africa and the surrounding regions of the order of several millimeters per day. Farther eastward, anomalously dry conditions are simulated over the equatorial Indian Ocean, consistent with the observations. The model fails to simulate the anomalously dry conditions observed near $20^{\circ} \mathrm{S}$ and eastward of $60^{\circ} \mathrm{E}$. As will be shown below, this particular feature will be simulated more realistically when the tropical Pacific SST anomalies are included in forcing the model. In summary, our Indian Ocean-only experiment shows clearly that the climatic conditions over eastern equatorial Africa and the adjacent ocean areas are sensitive to Indian Ocean SST anomalies.

Anomalously low pressure is simulated over the regions with enhanced SST and rainfall, and the horseshoe-type pattern of anomalously strong rainfall and anomalously high SST is seen also in the sea level pressure anomaly field (not shown). This is consistent with a thermal response. Farther to the west, positive sea level pressure anomalies were simulated covering most of Africa in the region $15^{\circ} \mathrm{N}-15^{\circ} \mathrm{S}$. Strongest anomalous surface wind convergence is found near the equator off the western boundary in the region $40^{\circ}-$ $55^{\circ} \mathrm{E}$ (not shown), where we find also the strongest rainfall response. Strong anomalous surface wind divergence is simulated farther westward in the region $20^{\circ}-35^{\circ} \mathrm{E}$. Surface temperatures are strongly reduced over eastern equatorial Africa, with maximum temperature anomalies of about $-4^{\circ} \mathrm{C}$ in Kenya. All these features are statistically highly significant, as revealed by $t$ tests.

Additional sensitivity experiments were conducted in order to explore the model's sensitivity to different SST anomaly patterns. These sensitivity experiments were performed at T21 resolution. The T21 model was forced by all three different tropical SST anomaly patterns shown in Fig. 2. In the first experiment, the SST anomalies in the Indian Ocean only were prescribed, as in the experiment with the T42 model version described above. In the second experiment, the SST anomalies in the Pacific Ocean only were prescribed, while in the third experiment, both the tropical Indian Ocean and Pacific Ocean SST anomalies were prescribed. Again five-member ensembles of 90-day integrations were performed, the results averaged over all 90 days, and the ensemble mean responses shown. 
a.) SST anomalies for experiment INDI

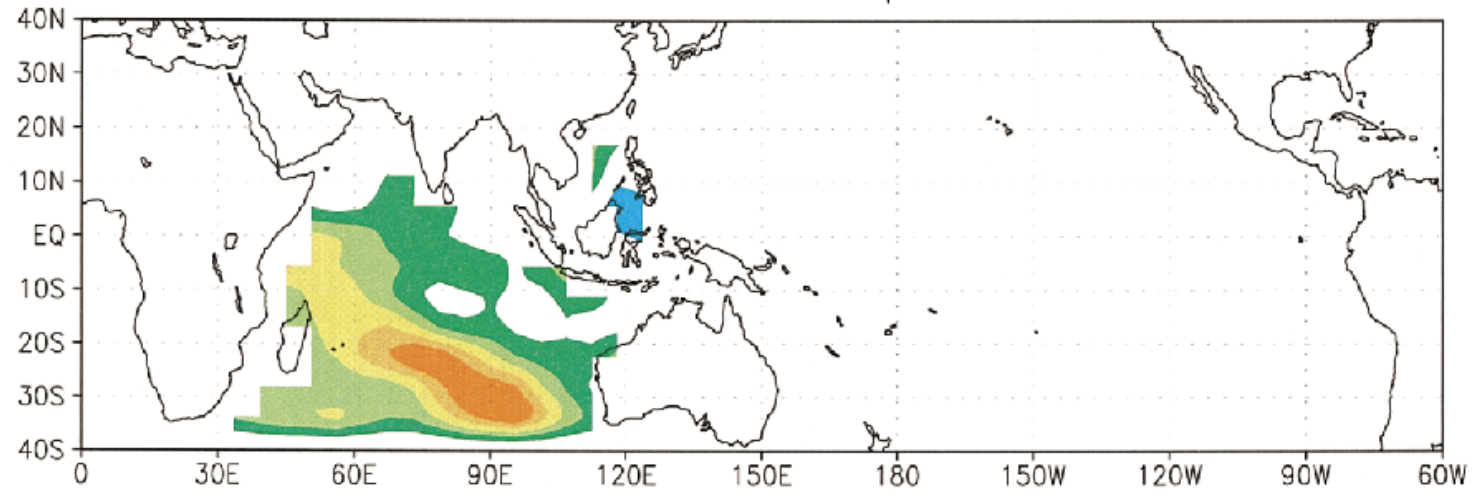

b.)

$\mathrm{PACl}$

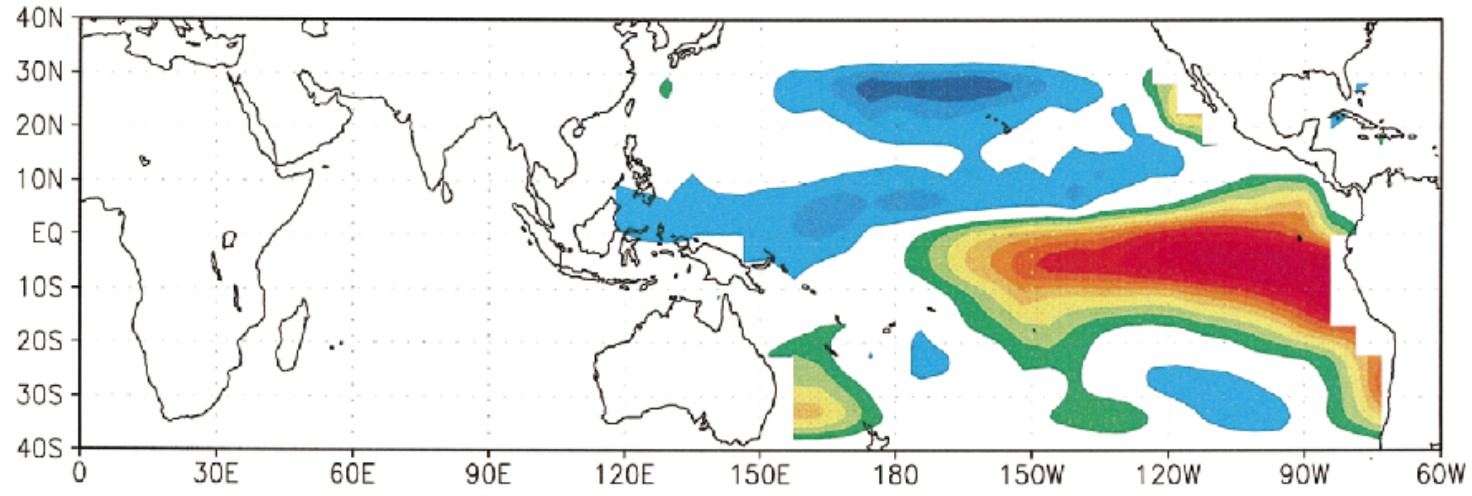

c.)

INPA

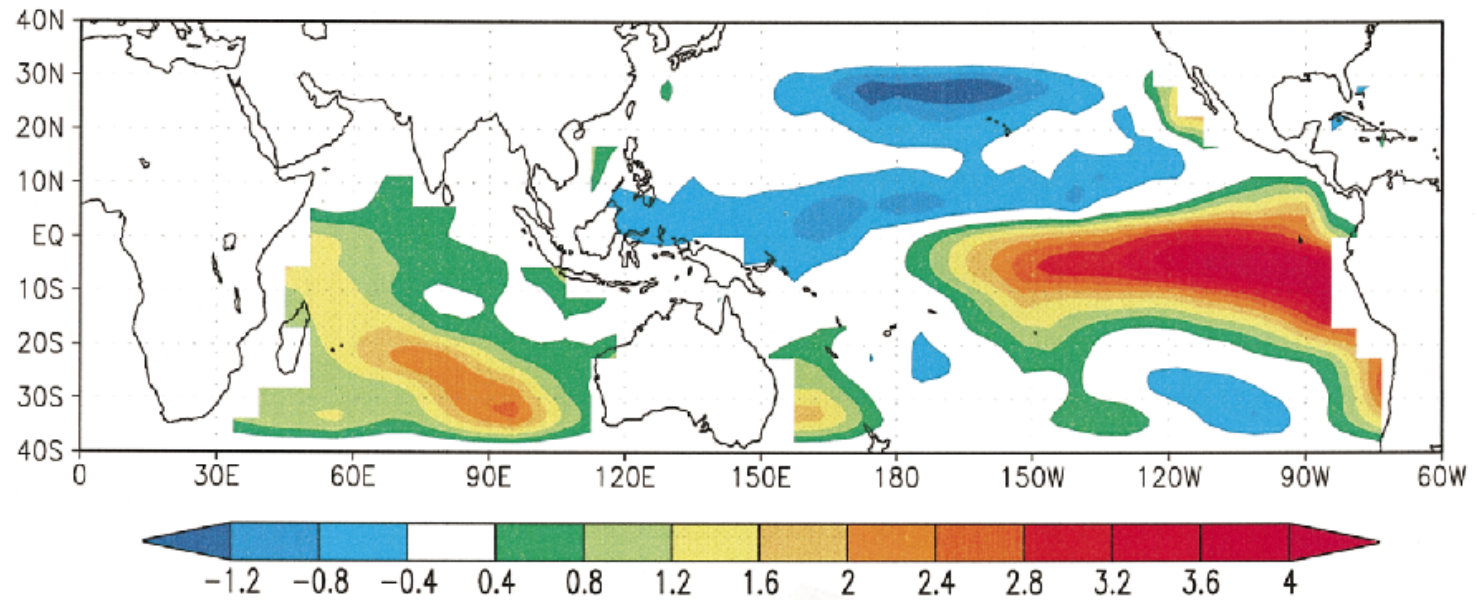

FIG. 2. The three SST anomaly patterns $\left({ }^{\circ} \mathrm{C}\right)$ used in the response experiments with the ECHAM3 atmosphere model. (a) The Indian Ocean part, (b) the Pacific Ocean part, and (c) the complete Indo-Pacific SST anomaly observed during the period Dec 1997-Jan 1998. 
The Indian Ocean experiment reproduced the main features simulated by the higher-resolution version (Fig. $4 a)$, verifying that the decrease in the resolution of the sensitivity experiments is not critical. The main result of the remaining sensitivity experiments was that the Pacific Ocean SST anomaly fails to produce the observed anomalies over eastern equatorial Africa and the adjacent ocean areas. While the observations show enhanced precipitation in this region (Fig. 3a), reduced precipitation is simulated in the Pacific Ocean experiment (Fig. 4b). Thus, our modeling study indicates it is the Indian Ocean SST anomalies rather than the Pacific Ocean SST anomalies that forced the strong precipitation anomalies over eastern equatorial Africa during December-January 1997/98. The response experiment in which both the Indian and Pacific Ocean SST anomalies were prescribed (Fig. 4c) can be interpreted to first order as the linear superposition of the first two experiments, which can be inferred from the sum of the responses of the first two experiments (Fig. 4d). The inclusion of the Pacific SST anomalies, however, improves somewhat the simulation of the rainfall anomalies over the Indian Ocean near $20^{\circ} \mathrm{S}$ by weakening the excessive rainfall anomalies seen in Figs. $3 \mathrm{~b}$ and $4 \mathrm{a}$.

Since the result that the Indian Ocean SST anomalies rather than the Pacific SST anomalies forced the rainfall anomalies over eastern equatorial Africa is an important one, we performed additional ensemble experiments that are not shown here. In particular, we repeated the Pacific-only experiment with the higher-resolution T42 version of our model and found a similar result to that obtained with the T21 model: The Pacific SST anomalies did not drive the heavy rainfall over eastern equatorial Africa and yielded even the wrong sign. Thus, we are rather confident that the connection between Indian Ocean SST anomalies and eastern equatorial African rainfall is real. We note, however, that the Indian Ocean SST anomalies observed during winter 1997/98 were highly exceptional both in strength and pattern, and that our results should not be generalized.

\section{Discussion}

Our results indicate that SST anomalies in the Indian Ocean were important in December-January 1997/98 in forcing climate anomalies over eastern Africa. This link between the Indian Ocean SST and the climate over eastern Africa provides some hope for seasonal climate forecasting in this region, provided that the SST anomalies themselves are predictable. It has been shown that the Indian Ocean SSTs respond to the SST fluctuations in the tropical Pacific with a time lag of a few months (Klein et al. 2000; Venzke et al. 1999). This response is a mixed layer response to anomalous surface heat fluxes forced by the SST anomalies in the tropical Pacific. Thus, short-range predictions of Indian Ocean SST anomalies appear possible to the extent that ENSO itself is predictable. An example has been shown, for instance, by Latif and Barnett (1995), who used a hybrid coupled model to study the interactions between the tropical oceans and to hindcast western equatorial Indian Ocean SST anomalies during and after the strong El Niño of 1982/83.

The amount of variance in southwestern Indian Ocean SST variability explained by ENSO amounts to about 50\% if the winter season (DJF) is considered, which was revealed by an analysis of seasonal SST anomalies for the period 1979-98. The fraction of variance explained by ENSO increases somewhat (up to about $60 \%$ ) when a lag of one season is introduced, with the southwestern Indian Ocean SST lagging. The period considered, however, was a relatively active ENSO period, and the explained variance in southwestern Indian Ocean SSTs is reduced to about 30\%, when the period 1950-98 is used. Thus, a large part of the interannual SST variability in the Indian Ocean is not related to ENSO. Furthermore, the structure of the SST anomaly observed during the El Niño winter $1997 / 98$ that was used in this study was somewhat unusual, and the strong SST anomaly in the southern part of the Indian Ocean (Fig. 2a) does not fit the canonical ENSO response structure, which is characterized by a more uniform and tropically confined SST anomaly pattern (Venzke et al. 2000).

It is likely, however, that the strong Indian Ocean SST anomaly observed in winter 1997/98 was forced remotely by the SST anomalies in the Pacific. In order to demonstrate this, we show in Fig. 5 the anomalous surface heat flux for the winter (DJF) 1997/98 as simulated in an integration with the T42 version of the atmosphere model ECHAM4 driven with the Pacific SST anomalies only. This experiment is described in detail by Grötzner et al. (1999, manuscript submitted to Quart. J. Roy. Meteor Soc.). Significant positive heat flux anomalies, which would tend to warm the ocean, are simulated in a band extending from the southwestern equatorial Pacific in a southeastward direction. A detailed discussion of the origin of the Indian Ocean SST anomaly is beyond the scope of this paper, but Fig. 5 indicates strongly that the Pacific played a major role.

In summary, we have shown that the Indian Ocean SST is able to play an active role in forcing climate anomalies over eastern Africa and that such a situation occurred during December and January 1997/98. This has important implications for the development of climate forecast models. Many models used today couple only a tropical Pacific basin ocean model to a regional or global atmosphere model. Such models lack important interactions within and between the tropical oceans and may therefore lose the potential to predict climate anomalies over eastern Africa. Furthermore, our results indicate that an observational network in the Indian Ocean should be established, in order to improve our 

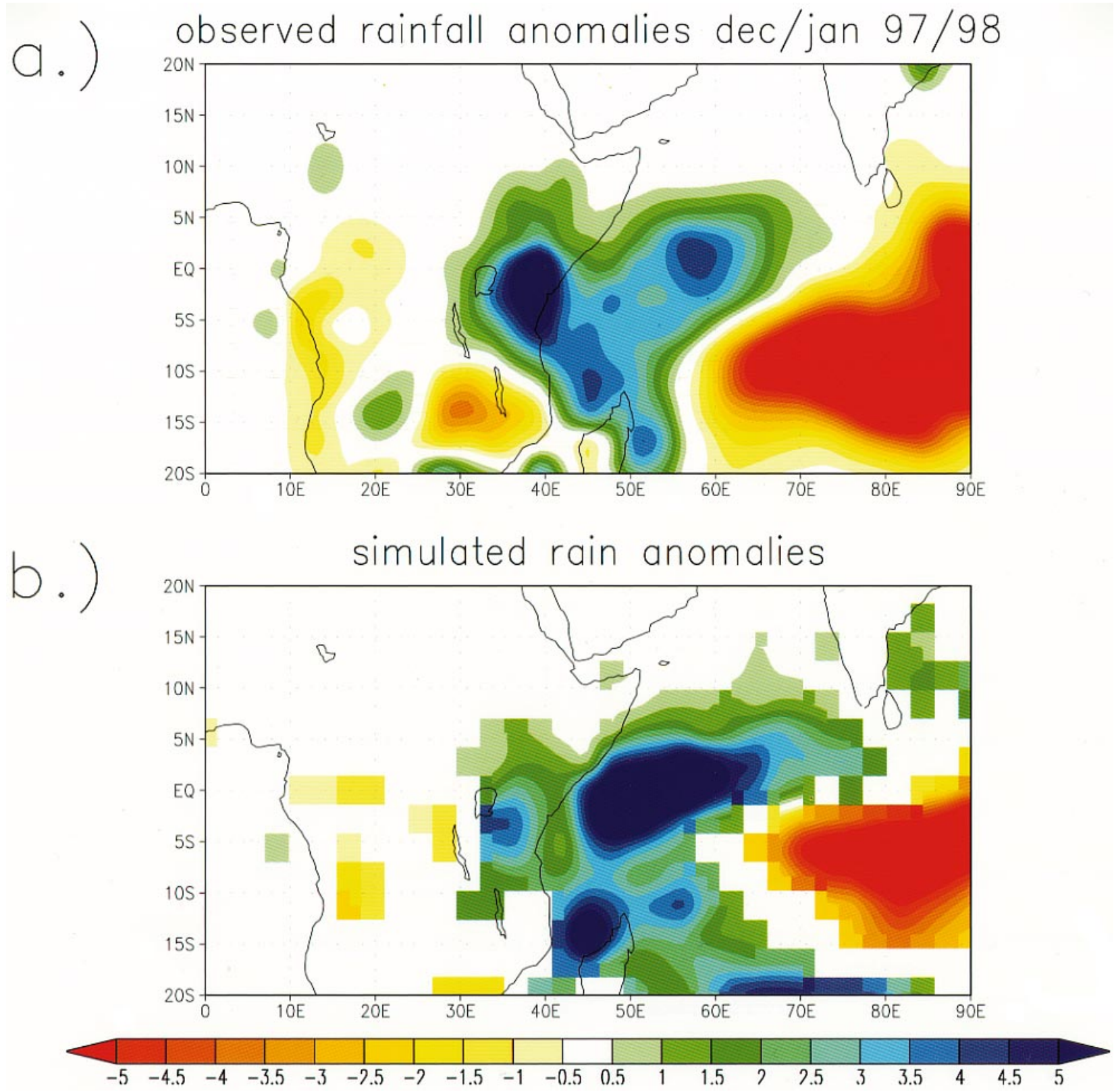

FIG. 3. (a) Observed rainfall anomalies $\left(\mathrm{mm} \mathrm{day}^{-1}\right)$ during the period Dec 1997-Jan 1998. (b) The atmosphere model ECHAM3 (T42) simulated rainfall anomalies $\left(\mathrm{mm} \mathrm{day}^{-1}\right)$ with Indian Ocean SST anomalies prescribed. The model response shown is the mean over all five realizations. Shown are the anomalies (relative to a 30-yr control run with climatological SSTs) that exceed the 95\% significance level according to a $t$ test.

understanding of the processes that govern the interannual SST fluctuations in this region. Such an observing system should monitor not only surface quantities but also subsurface quantities. There are, for instance, indications from altimetric sea surface height observations (TOPEX/Poseidon) that interannual baroclinic Rossby waves affect the SST in the Indian Ocean near $10^{\circ} \mathrm{S}$ (Chambers et al. 1999).
Acknowledgments. We thank Dr. C. Eckert, Dr. M. Münnich, and Dr. S. Venzke for their input to this paper. This work was funded by the European Union through the PROVOST and SINTEX projects. M. Dima was supported by the visiting scientists program of the Max Planck Society. The atmosphere model integrations were performed at the Deutsches Klimarechenzentrum. 
a.)

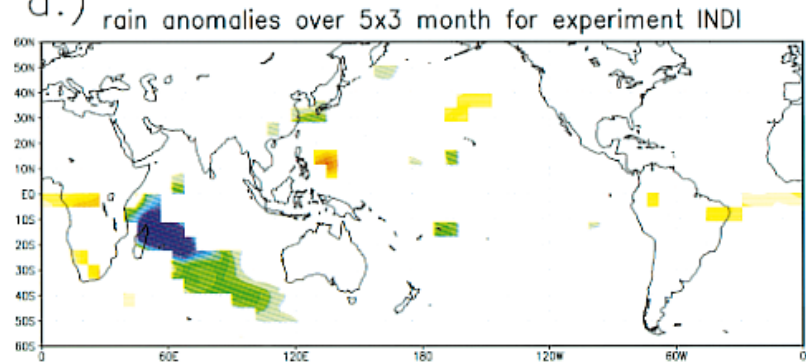

b.)

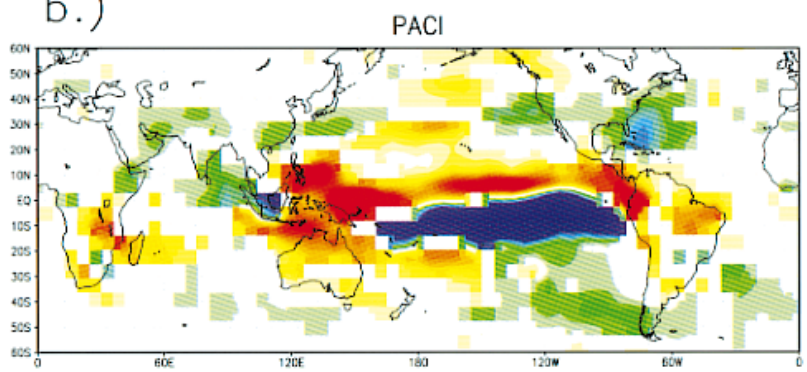

c.)

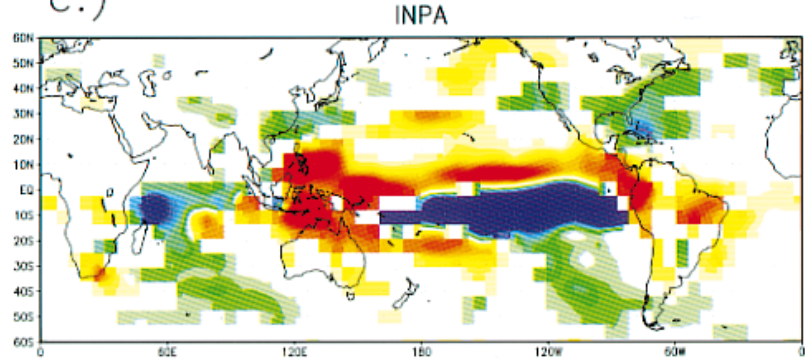

d.)

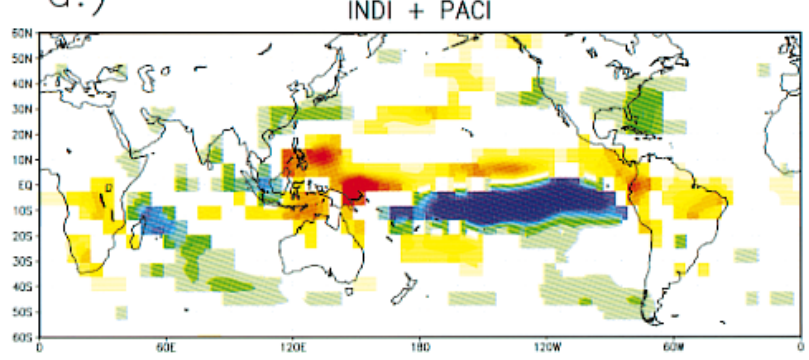

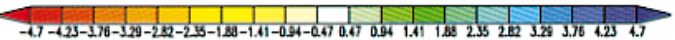

FIG. 4. Ensemble mean precipitation responses $\left(\mathrm{mm} \mathrm{day}^{-1}\right)$ of the atmosphere model ECHAM3 (T21) to the SST anomaly patterns shown in Fig. 2. (a) Response to the Indian Ocean SST anomaly, (b) response to the Pacific Ocean SST anomaly, (c) response to the complete Indo-Pacific SST anomaly, and (d) linear superposition of the responses shown in (a) and (b). Shown are the anomalies (relative to a 50yr control run with climatological SSTs) that exceed the 95\% significance level according to a $t$ test.

\section{anom. surf. heat flux (DJF 1997/1998), Pac.-only exp.}
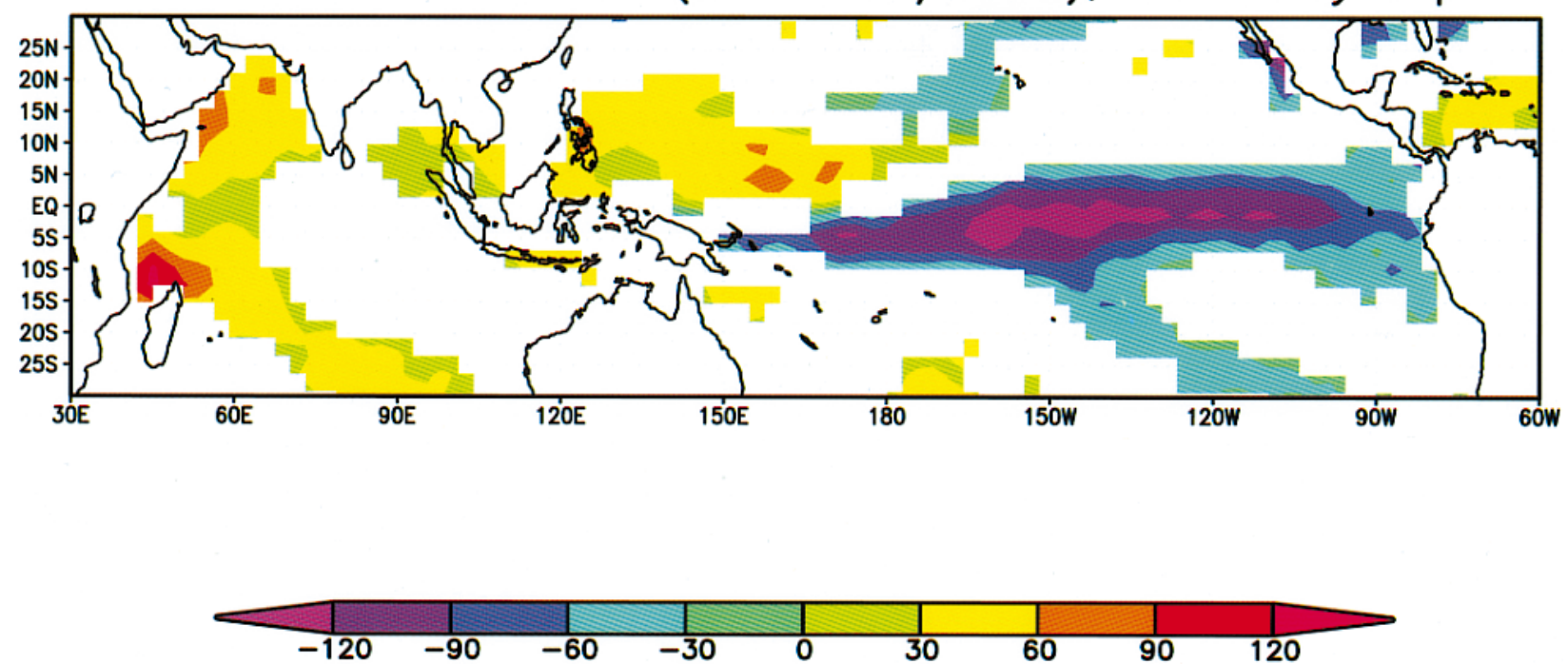

FIG. 5. Ensemble mean surface heat flux response $\left(\mathrm{W} \mathrm{m}^{-2}\right)$ of the atmosphere model ECHAM4 (T42) to the Pacific SST anomalies observed during winter (DJF) 1997/98. The model response shown is the mean over all 10 realizations performed. Shown are the anomalies (relative to a 26-yr run with observed SSTs for the period 1979-94) that exceed the 95\% significance level according to a $t$ test. Further details can be obtained from Grötzner et al. (1999, manuscript submitted to Quart. J. Roy. Meteor. Soc.). 


\section{REFERENCES}

Arpe, K., L. Dümenil, and M. A. Giorgetta, 1998: Variability in the Indian Monsoon in the ECHAM3 model: Sensitivity to sea surface temperature, soil moisture, and the stratospheric quasi-biennial oscillation. J. Climate, 11, 1837-1858.

Cane, M. A., G. Eshel, and R. W. Buckland, 1994: Forecasting Zimbabwean maize yield using eastern equatorial Pacific sea surface temperature. Nature, 370, 204-205.

Chambers, D. P., B. D. Tapley, and R. H. Stewart, 1999: Anomalous warming in the Indian Ocean coincident with El Niño. J. Geophys. Res., 104, 3035-3047.

Folland, C. K., T. N. Palmer, and D. E. Parker, 1986: Sahel rainfall and world-wide sea surface temperatures. Nature, 320, 602-607.

- J. Owen, N. M. Ward, and A. Colman, 1991: Prediction of seasonal rainfall in the Sahel region using empirical and dynamical methods. J. Forecast., 10, 21-56.

Klein, S. A., B. J. Soden, and N.-C. Lau, 1999: Remote sea surface temperature variations during ENSO: Evidence for a tropical atmospheric bridge. J. Climate, 12, 917-932.

Lamb, P. J., and R. A. Peppler, 1987: North Atlantic oscillation: Concept and an application. Bull. Amer. Meteor. Soc., 68, 12181225 .

- and — - 1991: West Africa. Teleconnections Linking Worldwide Climate Anomalies, M. H. Glantz, R. W. Katz, and N. Nicholls, Eds., Cambridge University Press, 121-189.

Latif, M., and T. P. Barnett, 1995: Interactions of the tropical oceans. J. Climate, 8, 952-964.

Makarau, A., and M. R. Jury, 1997: Predictability of Zimbabwe summer rainfall. Int. J. Climatol., 17, 1421-1432.

Neelin, J. D., D. S. Battisti, A. C. Hirst, F.-F. Jin, Y. Wakata, T. Yamagata, and S. Zebiak, 1998: ENSO theory. J. Geophys. Res., 103, 14 261-14 290.
Nicholls, N., 1989: Sea surface temperatures and Australian winter rainfall. J. Climate, 2, 965-973.

Palmer, T. N., 1986: Influence of the Atlantic, Pacific, and Indian Oceans on Sahel rainfall. Nature, 322, 251-253.

Philander, S. G. H., 1990: El Niño, La Niña and the Southern Oscillation. Academic Press, 293 pp.

Reynolds, R. W., and T. M. Smith, 1994: Improved global sea surface temperature analyses using optimum interpolation. J. Climate, 7, 929-948.

Roeckner, E., and Coauthors, 1992: Simulation of the present-day climate with the ECHAM model: Impact of model physics and resolution. Max-Planck-Institut für Meteorologie Report 93, 172 pp. [Available from Max-Planck-Institut für Meteorologie, Bundesstrasse 55, D-20146 Hamburg, Germany.]

Ropelewski, C. F., and M. S. Halpert, 1989: Precipitation patterns associated with the high index phase of the Southern Oscillation. J. Climate, 2, 268-284.

Rowell, D. P., C. K. Folland, K. Maskell, J. A. Owen, and N. M. Ward, 1992: Modelling the influence of global sea surface temperatures on the variability and predictability of seasonal Sahel rainfall. Geophys. Res. Lett., 19, 905-908.

Stockdale, T. N., D. L. T. Anderson, J. O. S. Alves, and M. A. Balmaseda, 1998: Global seasonal rainfall forecasts using a coupled ocean-atmosphere model. Nature, 392, 370-373.

Venzke, S., M. Latif, and A. Villwock, 2000: The coupled GCM ECHO-2. Part II: Indian Ocean response to ENSO. J. Climate, in press.

Ward, N. M., 1998: Diagnosis and short lead time prediction of summer rainfall in tropical North Africa at interannual and multidecadal timescales. J. Climate, 11, 3167-3191.

Xie, P., and P. A. Arkin, 1997: Global precipitation: A 17-year monthly analysis based on gauge observations, satellite estimates and numerical model outputs. Bull. Amer. Meteor. Soc., 78, 25392558. 